\title{
Clinical Legal Education in Asia - Accessing Justice for the
}

Underprivileged, edited by Shuvro Sarker (Palgrave Macmillan), 2015, 288pp, £65 (hardback), ISBN 978-1-137-51752-4

Asia has slowly but surely been emerging as an exciting addition to the clinical legal education (CLE) family. This text is therefore a timely publication, drawing attention to the development and current state of CLE in the East. The book aims to provide "the history, present status, and possible future models of clinical legal education" in Asia. To that end it comprises 12 chapters organised by country, from Turkey travelling to Japan and covering all regions in between, namely, Israel, Palestine, India, Sri Lanka, China, Thailand, Hong Kong, Singapore, South Korea and Taiwan. Collectively the sections provide a striking overview of CLE with each chapter locating clinic in the context of its regional characteristics.

Editor Shuvro Prosun Sarker, who is fast developing a reputation of being a figurehead for legal education in Asia, has curated an insightful set of essays. The list of contributors is extensive, embracing well known global clinicians, such as Bruce Lasky, and emerging names from the region.

The text has an accessible structure; there is an overarching introduction which briefly outlines the history of CLE and the characteristics of Asian clinical approaches. The extensive list of conferences held since 2005, listed in Chapter 1, is probably only of interest to diehards but it does demonstrate how quickly the power of CLE can spread and take hold. Each of the following 12 chapters focuses 
on a particular country so one can dip in and out to suit one's interests. Content wise, the book guides the reader through some of the most developed CLE regions (eg India) to newcomers such as China (which developed CLE programmes in 2000) to those still struggling to gain a foothold on the clinical ladder (eg the Maldives). Over approximately 20 pages each, the respective chapters provide a sound synopsis of how CLE operates in a particular jurisdiction. This summary is supplemented by helpful references to additional sources for readers wishing to delve further into the scholarship.

Sarker identifies that CLE in Asia is characterised by empowerment, justice and skills, topics which permeate the whole book. The text also addresses the familiar issues of social justice, clinic as a tool for bridging the gap between legal education and practice, and a variety of pedagogical models, which readers from across the globe will be able to relate to. There are a range of themes which emerge from the text, all of which provide food for thought. The importance of sustainability is noted; the influence of socio-political and economic factors on clinical success and design is also apparent. Collaboration has clearly played a crucial role in establishing and maintaining the respective projects featured in the text. This latter point provides an opportune reminder, particularly to UK clinicians and indeed governments, as we see the erosion of third sector agencies in these continuing times of austerity.

It was particularly interesting to learn about the endeavours of clinical projects in rural areas and the challenges this can bring. That has not stifled creativity 
however, with countries offering assistance in the areas such as farmer's justice (China). The breadth of CLE projects is also impressive addressing the rights of the disadvantaged, women's rights and labour rights (China) people living with HIV (Vietnam) and transgender rights (Thailand). CLE in Asia is in its infancy but this has benefit of fresh perspective, youthful enthusiasm and innovation, as is evidenced in some of the clinical projects explored in this book. Despite being in its formative years, experienced clinicians will enjoy reading about, and indeed can learn from, the myriad of models employed by our Asian clinical cousins. The range of case studies, statistical data and student feedback which feature in the book are equally informative.

Whilst the story of CLE in Asia is largely positive, the book does not gloss over the barriers faced in establishing and embedding the pedagogy. Despite best efforts, CLE has failed to gain any traction in the Maldives. Whilst it may seem incongruous for this chapter to be included alongside its more successful neighbours, it provides helpful insights into what obstacles exist and how these pitfalls might be avoided in future projects.

In terms of target audience the book will naturally be of particular interest to clinicians. However its appeal will also extend to legal educators more generally, since each chapter positions CLE within the broader legal and educational framework of the respective countries. It will be an invaluable reference point for Asian based academics seeking to engage with CLE or establish a clinic in the area, or global practitioners looking to work in the locality. 
In some respects our Asian counterparts are more radical in their adoption of CLE programmes, with several universities imposing mandatory pro bono work (eg Taiwan and Singapore). For this reason the text has the potential to reinvigorate established clinicians providing renewed impetus, and inspire colleagues new to the field.

The price of the book may be slightly prohibitive for some clinics and small law school libraries operating on a tight budget and it is hoped that a paperback will soon make an appearance to help disseminate more widely the great practice that is emerging from Asia. Failing that, an ebook is available.

The book has received positive reviews from leading voices who have worked extensively in the realm of Asian CLE. Frank Bloch proclaims that the book "offers important insights into the evolution of clinical programs throughout the region. Its various chapters demonstrate a shared commitment to the social justice mission of clinical legal education that is emblematic of a vibrant global clinical movement. It is an important addition to the growing literature on the spread of clinical legal education around the world." [backcover comment]

This is indeed "an opportunity to reflect on the curious lineage within which this branch of legal education has developed." However, as comprehensive as this text is, an additional final chapter drawing together all of the themes and future direction of travel would have resulted in a less abrupt ending to the travels through the Asian clinical world. Nonetheless, as contributors Marsh and Ramsden proclaim, this is indeed a "dynamic corner of the globe" and this book is a delight to read. I look 
forward to watching with interest how Asian continues to build its CLE projects as this book evidences, it has certainly laid strong foundations.

Victoria Murray

Northumbria University v.murray@northumbria.ac.uk 